\title{
Exercise test and 24-hour heart rate recording in men with high and low casual blood pressure levels
}

\author{
THOMAS THULIN AND OLOF WERNER \\ From the Unit for Community Care Sciences, Dalby; and the Department of Clinical Physiology, \\ University Hospital, Lund, Sweden
}

SUMMARY A population survey in a mixed suburban-rural community included a casual blood pressure recording.

From a total of 780 men not under treatment for hypertension those with blood pressures above the 95th centile between the ages of 20 and 59 years were selected (group A). Age-matched controls were selected among those with blood pressures below the 30th centile (group B). There were 31 subjects in each group.

Those in group A weighed significantly more than those in group B, and their obesity index was significantly higher. There were no significant differences between the groups in radiological heart volume, physical working capacity, or vital capacity.

The heart rate during exercise was significantly higher in group $A$ than in group $B$. The same difference in heart rate between the two groups was seen in the recumbent position before as well as after rest in the clinic. Interestingly, no differences in heart rate between the two groups could be shown outside the clinic on a continuous 24-hour electrocardiogram. This may indicate that the group with the higher blood pressures were 'hyperreactive' when exposed to the mental stress of being examined at the clinic.

The differences in blood pressure between the groups persisted at a repeated casual blood pressure $\overrightarrow{\vec{O}}$ measurement three years after the initial examination and similar differences in blood pressure were also $\frac{0}{3}$ found after rest and during exercise.

An increased heart rate has been observed in borderline hypertension (Paffenbarger et al., 1968; Sannerstedt, 1969; Frohlich et al., 1970; Julius and Schork, 1971; Berglund et al., 1974) though asymptomatic subjects with high blood pressure seem to respond to exercise in much the same way as those who are normotensive, at least with regard to the observed blood pressure and heart rate increase (Sannerstedt, 1966; Lund-Johansen, 1967).

Repeated blood pressure recordings at home on subjects with different levels of pressure have shown that such differences persist away from hospital (Sokolow et al., 1966; Julius et al., 1974), but apparently, it has not been determined whether differences in heart rate also persist.

In the present study two groups, respectively with high and low blood pressures in relation to the population in general, were selected from a group of 780 men not under treatment for hypertension (Thulin et al., 1978).

Received for publication 30 May 1977
They were studied with respect to differences in $\stackrel{\mathbb{D}}{=}$ body weight, heart volume on chest $x$-ray, vital $\frac{5}{3}$ capacity, response to exercise, and heart rate in the clinic and during 24 hours of normal activity.

\section{Subjects}

The subjects examined were selected from those of a N previous survey (Bengtsson, 1972) performed in the Dalby community in 1969-1970 consisting of 780 men not under treatment for hypertension. In that $\tilde{\omega}$ study blood pressure was measured under $\operatorname{stan}$ ? dardised conditions (Thulin et al., 1978) and thoseo with blood pressures above the 95th centile (group $\bar{D}$ A) were identified. This group originally contained? 33 subjects but one of them died of myocardial infarction in 1972, and another moved $500 \mathrm{~km}$ 宁 away and had to be excluded, leaving, therefore, $31 \stackrel{\mathrm{D}}{\stackrel{\mathrm{O}}{\circ}}$ subjects. An age-matched control was selected $\mathbb{Q}$ for each member of group A from those subjects in the survey with blood pressures below the 30tho 
centile. The 31 controls are referred to as group B.

The subjects in group A were selected if systolic blood pressure, diastolic blood pressure, pulse pressure, or any additive combination of these exceeded the 95th centile within the 4 age-groups 20 to 29,30 to 39,40 to 49 , and 50 to 59 years of age. Subjects were chosen for group B if the systolic and the diastolic blood pressures both fell within the 30th centile but pulse pressure was not used as a selection criterion in order to avoid including men with a low pulse pressure in combination with a raised diastolic pressure.

In 1972 the ages of groups A and B were $38 \pm 10$ and $40 \pm 12$ years (mean $\pm S D$ ), respectively.

No subject had symptoms and none was taking any drug known to influence the variables studied.

\section{Methods}

The study consisted of three parts. The first was carried out at Dalby in 1972. On this occasion, the participants received a medical examination which included blood pressure measurements, an electrocardiogram, vital capacity, and a chest $x$-ray for the determination of heart volume.

The second and third parts of the investigation were performed at the Department of Clinical Physiology in Lund during 1972 to 1973 and 1973 to 1974, respectively. The second part comprised an exercise test on a bicycle ergometer, the third a continuous 24-hour ambulatory electrocardiographic recording on tape.

All subjects went through the first and the second parts. One man from each of groups $A$ and $B$ declined to participate in the 24-hour electrocardiograph study.

\section{FIRST EXAMINATION}

The investigations were performed between 7.30 and 10.00 am during January to May and September to December. The subjects fasted and had been requested not to smoke for at least 10 hours.

Height and weight were measured according to the WHO recommendations (Rose and Blackburn, 1968). Body surface area was calculated as weight $^{0.425}(\mathrm{~kg}) \times$ height $^{0.725}(\mathrm{~cm}) \times 71.84(\mathrm{Du}$ Bois and Du Bois, 1916). Relative body weight was calculated as weight $(\mathrm{kg}) /[$ height $(\mathrm{cm})-100]$ and as an index of obesity the quotient :weight $(\mathrm{kg}) / \mathrm{height}^{3}$ (m) $\left(\mathbb{W} / \mathrm{H}^{3}\right)($ Zilva and Nicholson, 1960) was used. Arm circumference was measured at the middle of the blood pressure cuff and recorded to the nearest $0.5 \mathrm{~cm}$.

The blood pressure was measured in the right arm in a standardised way (Thulin et al., 1975) with a mercury manometer before and after 10 to 15 minutes of rest supine. The blood pressure was also measured in the left arm and after 1 minute in the upright position. When the arm circumference was more than $30 \mathrm{~cm}$ an arm cuff with a rubber bladder measuring $15 \times 43 \mathrm{~cm}$ (Thulin et al., 1975) was used. Otherwise the cuff was standard with a rubber bladder measuring $12 \times 35 \mathrm{~cm}$. Systolic blood pressure (SBP) and diastolic (phase 5) blood pressure (DBP) were determined to the nearest 5 mmHg. All blood pressures were taken by one observer (TT).

Mean arterial blood pressure (MAP) was estimated as DBP $+\frac{\text { SBP }- \text { DBP }}{3}$ (Rushmer, 1961).

The heart rate (beats/min) was calculated from the radial pulse over a period of 30 seconds.

The electrocardiogram was recorded on 12 standard leads (I, II, III, aVR, aVL, aVF, V1, V2, V3, V4, V5, and V7), on a three-channel directwriting cardiograph (Elema-Schönander). It was recorded after rest supine and was coded according to the Minnesota Code (Rose and Blackburn, 1968) by two observers (TT and OW) who settled any discrepancies in assessment by discussion. The amplitude of the $R$ wave in lead V5 was measured on the last ordinary beat in the record from each subject.

Heart volume was determined from the chest $x$ ray taken in the standing position by an experienced radiologist who had no other information regarding the subjects. The relative heart volume was given in $\mathrm{ml} / \mathrm{m}^{2}$ body surface area.

Lung function was examined with a vitalograph (Kifa). The vital capacity (VC) and the forced expiratory volume in one second $\left(\mathrm{FEV}_{1}\right)$ were measured.

\section{SECOND EXAMINATION}

\section{Exercise test}

The exercise test was carried out between 1 and 4 pm sitting on an electrically braked bicycle ergometer, as described by Karlefors (1966) but with the load graded in watts.

Blood pressure and respiratory rate were determined in the supine position after 10 minutes at rest and every 2 minutes during exercise. The blood pressure was also recorded immediately after exercise and after 4 and 10 minutes of a further period of supine rest. The heart rate was calculated from the electrocardiogram. Results of the diastolic blood pressure during and immediately after exercise, and 4 minutes later are however not presented because the measurements were considered unreliable (Karlefors et al., 1966). 
A standard 12 lead electrocardiogram (see above) was recorded on a six-channel ink jet recorder (Elema-Schönander) before and after exercise. The ST segment response was coded by two observers (TT and OW) after Punsar et al. (1968).

During exercise chest-head ( $\mathrm{CH}$ ) leads were recorded. Exercise started at $50 \mathrm{~W}$ and was increased by $50 \mathrm{~W}$ steps. It continued at each work load for at least 4 minutes until a 'steady state' was reached, that is when the heart rate at a given work load did not increase by more than 4 beats/minute during a 2-minute interval. The heart rate, blood pressure, and respiratory rate were measured every 2 minutes. In most subjects exercise was continued until exhaustion; in one, exercise was terminated because of an excessive rise in blood pressure. Another stopped prematurely because he was unaccustomed to bicycling.

\section{THIRD EXAMINATION}

\section{Heart rate during 24 hours}

An electrocardiogram was recorded continuously on a portable recorder (HRB2, SRA, Stockholm). The recorder weighed $450 \mathrm{~g}$ and was attached to the subject by a belt around the waist. A single bipolar lead was obtained by two electrodes placed on the chest. Two consecutive 12-hour tape recordings were taken. The subjects were instructed to carry on with their usual activities which they recorded on a preprinted form. Poor quality traces sometimes necessitated a re-recording of one of the 12-hour periods. In these cases the same hours of the day or night were covered.

The heart rate was measured from the electrocardiogram using a tape replay unit (HRA2, SRA Stockholm), and was written as a continuous graph on paper (heart rate versus time) from which the heart rate during different periods of the day or night was obtained by two independent observers (TT and OW).

The following measures of rate were made: (1) at rest on the examination couch after the start of the tape recording; (2) maximum; (3) minimum; (4) mean between 9 am and $3 \mathrm{pm} ;(5)$ mean between 9 $\mathrm{pm}$ and $3 \mathrm{am}$; (6) mean between $1 \mathrm{pm}$ and $4 \mathrm{pm}$; (7) after 1 to 2 hours work in the morning; (8) one hour before going to bed; (9) immediately after going to bed; and (10) after 2 to 3 hours of sleep.

In order to evaluate the precision with which these values could be extracted from the heart rate graph, the root mean square between-observer variation was calculated. This did not exceed 3 beats $/ \mathrm{min}$. Furthermore, no systematic between-observer differences were found.

\section{Statistical methods}

All the data were recorded on a previously prepared form and were later transferred to punched cards and double-checked.

Standard statistical methods were used to determine mean values, standard deviations, and correlation coefficients. Most of the calculations were performed at the Computer Centre in Lund. Statistical analyses were also made using an Olivetti Programma 101. The hypothesis that no differences existed between the two groups was checked with Student's $t$ test on the differences between matched pairs. Intra-individual differences within a group were also tested by the $t$ test for paired data.

\section{Results}

\section{ANTHROPOMETRIC MEASUREMENTS}

The results are shown in Table 1 . Mean height was identical in the two groups. Mean weight was significantly higher in group $\mathbf{A}(\mathbf{P}<0.01)$ than in group B. Body surface area was 5 per cent higher $(P<$. 0.05 ) in group $A$. The mean relative body weight and the mean index of obesity were significantly higher in group $A(P<0.001$ and $P<0.01$, respectively) than the corresponding mean values in group B. The mean arm circumference was not significantly different in the two groups.

HEART VOLUME, VITAL CAPACITY, AND FORCED EXPIRATORY VOLUME

The results are shown in Table 2. The absolute heart volume was significantly higher in group $A$ than in group $B(P<0.05)$. There was no significant difference between the groups in relative heart volume, mean vital capacity, and the mean forced expiratory volume during one second.

BLOOD PRESSURE

The difference in the mean casual systolic and $\frac{D}{O}$ diastolic blood pressures between groups $A$ and $B$

Table 1 Mean values $\pm S D$ for height, weight, body surface area, arm circumference, relative body weight, and index of obesity

\begin{tabular}{|c|c|c|c|}
\hline & $\begin{array}{l}\text { Group A } \\
\text { No. }=31\end{array}$ & $\begin{array}{l}\text { Group B } \\
\text { No. }=31\end{array}$ & $\boldsymbol{P}$ \\
\hline $\begin{array}{l}\text { Height }(\mathrm{cm}) \\
\text { Weight }(\mathrm{kg}) \\
\text { Body surface area }\left(\mathrm{m}^{2}\right) \\
\text { Arm circumference }(\mathrm{cm}) \\
\text { Relative body weight } \\
\text { Index of obesity }\end{array}$ & $\begin{array}{l}176 \pm 5 \\
78 \cdot 3 \pm 9.9 \\
1.94 \pm 1 \cdot 2 \\
29 \cdot 2 \pm 2 \cdot 1 \\
1 \cdot 03 \pm 0.13 \\
14 \cdot 4 \pm 1.9\end{array}$ & $\begin{array}{l}176 \pm 7 \\
70.2 \pm 8.6 \\
1.85 \pm 1 \cdot 4 \\
28.7 \pm 2.0 \\
0.93 \pm 0.09 \\
13.0 \pm 1.4\end{array}$ & $\begin{array}{l}\text { NS } \\
\star \star \\
\star \\
N S \\
\star \star \star \\
\star \star\end{array}$ \\
\hline
\end{tabular}


Table 2 Mean values $\pm S D$ for absolute heart volume, relative heart volume, vital capacity, and forced expiratory volume

\begin{tabular}{lcccc}
\hline & $\begin{array}{c}\text { Group } A \\
N=31\end{array}$ & $\begin{array}{l}\text { Group B } \\
N=31\end{array}$ & $P$ \\
\hline $\begin{array}{l}\text { Heart volume, } \\
\text { absolute }(\mathrm{ml})\end{array}$ & $790 \pm 162$ & $720 \pm 128$ & * \\
$\begin{array}{l}\text { Heart volume, } \\
\text { relative }\left(\mathrm{ml} / \mathrm{m}^{2}\right)\end{array}$ & $405 \pm 70$ & $388 \pm 61$ & $\mathrm{NS}$ \\
$\begin{array}{l}\text { Vital capacity (1) } \\
\begin{array}{l}\text { Forced expiratory } \\
\text { volume }(1 / \mathrm{s})\end{array}\end{array}$ & $\mathbf{4 . 4} \pm 0.8$ & $\mathbf{4 . 6} \pm 0.8$ & $\mathrm{NS}$ \\
\hline
\end{tabular}

at the time of selection (1969 to 1970) persisted at the follow-up examination in 1972.

The casual systolic blood pressure increased significantly in both groups between 1969 to 1970 and 1972, while the casual diastolic blood pressure remained unchanged at the follow-up examination (Table 3).

In Fig. 1 the casual blood pressure, the blood pressure after rest, and the blood pressure in the standing position measured in 1972 are shown as well as the corresponding heart rates.

The systolic blood pressure decreased after rest in groups $\mathrm{A}$ and $\mathrm{B}$ as compared with the casual measurement $(P<0.001$ and $P<0.01$, respectively). No difference was seen between the systolic blood pressure after rest and the systolic blood pressure in the standing position in either of the two groups. The diastolic blood pressure decreased after rest as compared with the casual measurement in group $A$ only $(P<0.001)$. The diastolic blood pressure increased on standing after rest in both groups $(P<0.001)$.

There was no consistent difference between the blood pressures in the two arms in either group.

\section{HEART RATE}

The mean heart rate was significantly higher in group A compared with group B both before and after rest $(P<0.01$ and $P<0.001$, respectively). No significant difference in mean heart rate between the groups was observed in the standing position (Fig. 1).

Table 3 Casual blood pressure 1969 to 1970 and the change in casual blood pressure at follow-up in 1972 in groups $A(N=31)$ and $B(N=31)$

\begin{tabular}{lllll}
\hline & Group & $\begin{array}{l}\text { Blood pressure } \\
1969-1970 \\
M \pm S D(\mathrm{mmHg})\end{array}$ & $\begin{array}{l}\text { Change in blood } \\
\text { pressure at follow-up } \\
1972 \\
M \pm S D(\mathrm{mmHg})\end{array}$ & $P$ \\
& & & & \\
& & & $+6 \pm 14$ & $\star$ \\
Systolic & A & $152 \pm 13$ & $+10 \pm 11$ & $\star \star \star$ \\
& B & $112 \pm 4$ & $+4 \pm 11$ & $\mathrm{NS}$ \\
Diastolic & A & $92 \pm 13$ & $+3 \pm 9$ & $\mathrm{NS}$ \\
& B & $72 \pm 5$ & $+3 \pm 9$
\end{tabular}
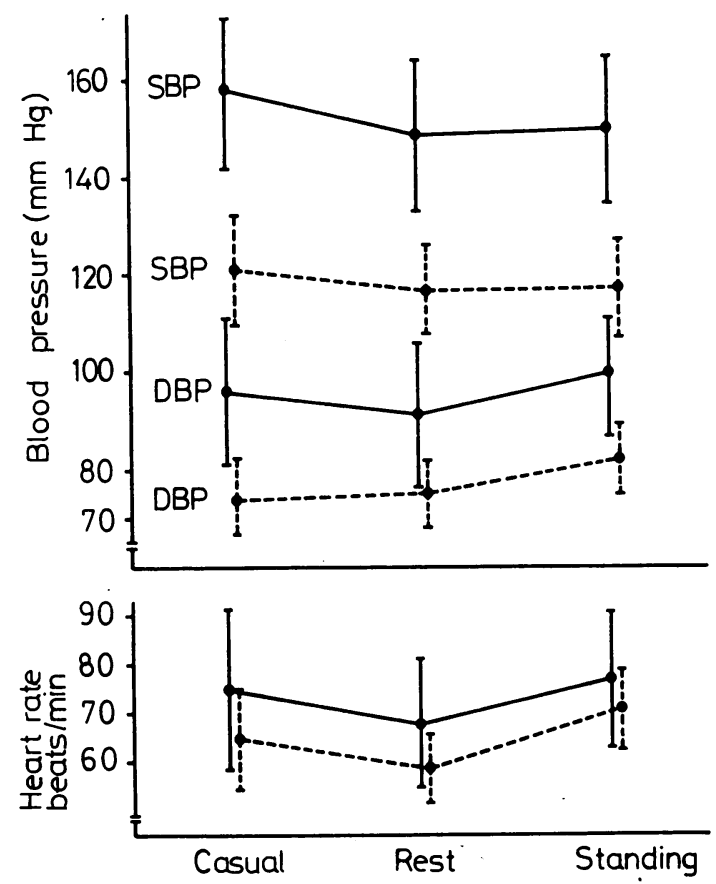

Fig. 1 Systolic and diastolic blood pressures and heart rates $(M \pm S D)$ before and after rest and in the standing position in group $A$ (-) and in group $B$ $(\ldots \ldots)$.

When the casual heart rate and the heart rate after rest were compared it was found there had been a decrease after rest of 7 beats $/ \mathrm{min}$ in group $A(P<$ $0.001)$ and of 6 beats $/ \mathrm{min}$ in group $B(P<0.001)$. The heart rate increased by 9 beats $/ \mathrm{min}$ in group $A(P<0.001)$ and by 13 beats $/ \mathrm{min}$ in group $\mathrm{B}(\mathbf{P}<0.001)$ on assuming the standing position after rest.

\section{DIURNAL HEART RATES}

The heart rate was measured on 10 occasions. The mean heart rates are shown in Fig. 2. No significant differences between the high and low blood pressure groups were found on any of these occasions. In addition, there were no differences between smokers and non-smokers.

\section{ELECTROCARDIOGRAM AT REST}

Sixteen subjects in group $A$ and 9 subjects in group $B$ had codable abnormalities according to the Minnesota code. No subject in group B and only one subject in group $A$ had codable $Q$ waves (code 1-3-4). Eight subjects in group $A$ and 4 subjects in group $B$ had high amplitude $R$ waves (code 3-1). The mean $R$ wave amplitude was $1.9 \pm 0.9 \mathrm{mV}$ in group $A$ and $1.9 \pm 0.8 \mathrm{mV}$ in group $B$. There were 


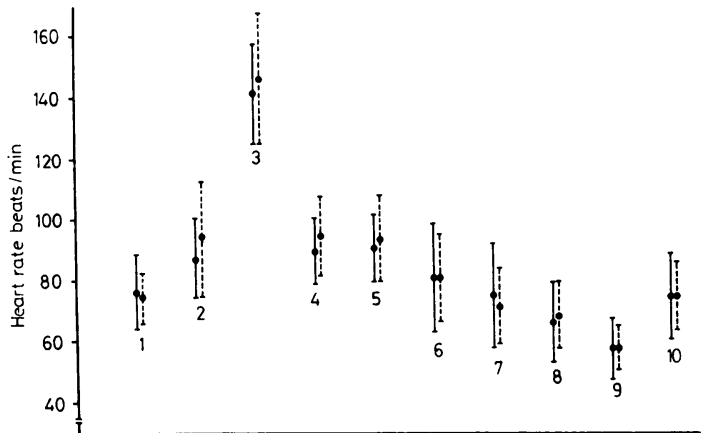

Fig. 2 Diurnal heart rates $(M \pm S D)$ from the 24-hour ambulatory tape electrocardiogram in group $A$ $(\longrightarrow$ ) and in group $B(\ldots .)$..1 At rest after start of recording; 2 after 1 to 2 hours' work; 3 maximum; 4 mean 9 am to 3 pm; 5 mean 1 to 4 pm; 6 one hour before going to bed; 7 after going to bed; 8 after 2 to 3 hours' sleep; 9 minimum; 10 mean $9 \mathrm{pm}$ to $3 \mathrm{am}$.

3 cases of $\mathrm{T}$ wave abnormality in group A (code 5-3 or 5-4), but none in group $B$.

\section{EXERCISE TEST}

All subjects reached an exercise level of at least 100 W, and most subjects $150 \mathrm{~W}$ (26 in group $A$ and 25 in group B). The mean physical working capacity was similar in the two groups $(195 \pm 39 \mathrm{~W}$ in group $A$ and $200 \pm 41 \mathrm{~W}$ in group B) and appeared to decrease with increasing age in both. The mean heart rate at maximum exercise was about the same in the two groups $(175 \pm 13$ beats $/ \mathrm{min}$ in group $\mathrm{A}$ and $172 \pm 14$ beats/min in group $B$ ) and did not

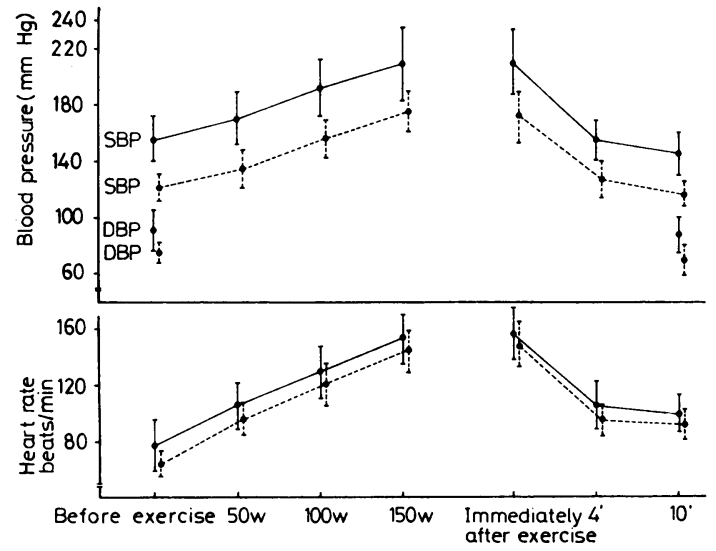

Fig. 3 Systolic blood pressure and heart rates $(M \pm$ $S D)$ before, during, and after exercise test in group $\bar{A}$ $(\longrightarrow)$ and in group $B(\ldots .$.$) . The diastolic blood$ pressure is shown before and 10 minutes after exercise only. Most subjects performed some minutes of work at 200 W, but many did not reach 'steady state'. seem to decrease with increasing age. The resting mean systolic and diastolic blood pressure and mean heart rate before exercise were all significantly higher in group A than in group B (Fig. 3). In essence, these results were similar to those obtained at rest in 1972 (see above). The differences in mean systolic blood pressure and in mean heart rate between the groups persisted at each work load up to $150 \mathrm{~W}$ and also immediately after and 4 and 10 minutes after exercise. The same was true for the mean diastolic blood pressure 10 minutes after exercise.

Electrocardiographic abnormalities during and after exercise were uncommon. Three subjects in group A and one subject in group B had frequent supraventricular extrasystoles for part of the test. One subject in group A had frequent ventricular extrasystoles throughout but had no other abnormality on his electrocardiogram. An 'ischaemic' (Punsar et al., 1968) ST segment response to exercise was found in 4 subjects in group $A$ and in 1 subject in group $B$.

\section{Discussion}

Several prospective studies have shown that a single casual blood pressure measurement has a high predictive value for future blood pressure readings (Pollack and Gudger, 1959; Harlan et al., 1962; Kannel et al., 1969; Hedstrand and Åberg, 1975). Our results show that the first casual blood pressure predicted subsequent casual blood pressure readings reasonably well (see Table 3 ), though slightly different methods for obtaining the blood pressures were used on the two occasions.

The existence of a relation between blood pressure and excess body weight has long been recognised (Bjerkedal, 1957; Kannel et al., 1966; Chiang et al., 1969). This was confirmed in the present study. Men in the higher blood pressure group weighed significantly more than the controls, though there $\triangle$ was no difference in mean height. The correlation $\frac{T}{0}$ between blood pressure and body weight as well as obesity has been shown to be real and not an effect of $\stackrel{\sim}{\sigma}$ spuriously high blood pressure readings in subjects with fat arms (Simpson et al., 1965).

We examined the hypothesis that the peripheral $c$ resistance was equal in the two groups and that the differences in blood pressure could be explained by $\stackrel{\varrho}{\subset}$ differences in cardiac output caused by an excess of $\Phi_{0}$ adipose tissue in the hypertensive one. The latter: were on average $8 \mathrm{~kg}$ heavier than the controls. Since the mean heights were equal, the excess

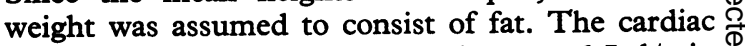
output of the controls was taken as $6.51 / \mathrm{min} \cong$ (Barratt-Boyes and Wood, 1958). Blood perfusion in one kilogram body fat was taken as $26 \mathrm{ml} / \mathrm{min} \Omega$ 
(Larsen et al., 1966). This gave an excess cardiac output in the hypertensive group of $0.21 / \mathrm{min}(3 \%$ more than in the controls), but since the mean arterial blood presuure in this group was about 25 per cent greater it is clear that the blood pressure difference was not caused solely by a difference in body fat.

An increased heart rate has been suggested as a predictor of clinical hypertension (Paffenbarger et cl., 1968; Julius and Schork, 1971; Berglund et al., 1974). A hyperkinetic circulation is often found in subjects with borderline arterial hypertension (Sannerstedt, 1969; Julius et al., 1971; Eich et al., 1972). In the present study, the mean heart rate was significantly higher in the recumbent position both before and after rest at the clinic in the hypertensives than in the controls, as was the mean heart rate during and after the exercise test. The absolute increase in heart rate during exercise was largely the same in the two groups.

The same differences in heart rate have been shown when normotensive men have been compared with others with early arterial hypertension without evidence of organic changes in the cardiovascular system (Sannerstedt, 1969; Sannerstedt et al., 1976).

In view of these results it is remarkable that the mean heart rates in the two groups did not differ on the 24-hour electrocardiograms. Perhaps the subjects with the higher blood pressure tended to be more sedentary than the controls, but this would not explain the similarity in heart rate during rest and sleep. A possible explanation could be that the subjects do not differ in their 'basal heart rate', but in their response to stress, whether psychic, for instance, when being examined by a nurse or a physician, or physiological, such as during exercise. In fact, hypertensives do tend to have a more 'anxious' personality profile, than normotensives (Julius, 1976) and also have a more intense blood pressure and heart rate response to psychic stress (Harris et al., 1953; Harburg et al., 1964). The same type of 'hyperreactivity' to mental stress has been shown in spontaneously hypertensive rats (Folkow et al., 1972). Since the subjects in the present study were exposed to the mental stress of being examined by a nurse at the time of selection, the design of the study does not allow us to state how much differences in 'hyperreactivity' rather than differences in 'basal blood pressures' have influenced their selection.

One of the measurements obtained from the tape recording was the heart rate while the subject was still lying on the examination couch. The fact that no significant difference between the groups with regard to this value could be shown may seem to contradict another result of this study, namely that the groups differed in heart rate after rest (Fig. 1). However, there were differences in the experimental setting. Firstly, the subjects usually had to rest about 20 to 30 minutes on the couch before the tape could be started. Possibly, this allowed subjects who were tense more time to relax. Secondly, during this period attention was concentrated mainly on technical matters related to the tape recording, and this too may have had the same effect.

Patients with established or severe hypertension tend to have a more rapid blood pressure increase during exercise than normal subjects (Sannerstedt, 1966; Lund-Johansen, 1967). In the present study the difference in blood pressure levels between the two groups persisted during exercise and did not increase with increasing work load. The same result has been seen when subjects with early hypertension have been compared with normal controls (Sannerstedt, 1966; Lund-Johansen, 1967).

Sokolow et al. (1966) have shown that the blood pressure decreases at home, but that differences in pressure between individuals at the clinic still persist. The present study has shown that the differences in heart rate between the two groups disappeared away from the clinic. This agrees well with the findings of Julius (1976), namely that borderline hypertension is not caused solely by a hyperkinetic circulation.

ST-T abnormalities at rest and during exercise were more frequent in the high blood pressure group than in the low blood pressure group. The number of ST-T abnormalities was small, but the result supports the findings of others (Wikstrand, 1976), who have shown that the prevalence of ST-T abnormalities increases with rising blood pressure. There was no difference between the two groups in $R$ wave amplitude in a left ventricular lead (V5).

In conclusion, the study has shown that asymptomatic and untreated men with the highest blood pressure levels in the population differ in anthropometric measurements as compared with men with low blood pressures. The differences in blood pressure persist during and after a graded exercise test. Furthermore, it appears that ST-T abnormalities are more frequent in the group with the highest blood pressure levels. Differences in heart rate were also observed but the results are equivocal, for it seems that differences in heart rate observed in the clinic do not persist during the normal activities of the subjects at home and at work.

We are grateful to Dr Torben Owman for examining the chest $x$-rays, and to Mr Bertil Sjöstedt and $\mathrm{Mr}$ Bo Zöger for statistical advice. We appreciate the 
criticism and suggestions given by Professor Håkan Westling and Associate Professor Bengt Scherstén. The work was supported by grants from the National Board of Health and Social Welfare and the Swedish Medical Research Council.

\section{References}

Barratt-Boyes, B. G., and Wood, E. H. (1958). Cardiac output and related measurements and pressure values in the right heart and associated vessels, together with an analysis of the hemodynamic response to the inhalation of high oxygen mixtures in healthy subjects. Fournal of Laboratory and Clinical Medicine, 51, 72-90.

Bengtsson, B. (1972). Some factors affecting the distribution of intraocular pressures in a population. Acta Ophthalmologica, 50, 33-46.

Berglund, G., Wilhelmsen, L., and Werkö, L. (1974). Blood pressure development and characteristics of subjects with moderate blood pressure elevation. Acta Medica Scandinavica, 196, 301-306.

Bjerkedal, T. (1957). Overweight and hypertension. Acta Medica Scandinavica, 159, 13-26.

Blackburn, H., Keys, A., Simonson, E., Rautaharju, P., and Punsar, S. (1960). The electrocardiogram in population studies. A classification system. Circulation, 21, 1160-1175.

Chiang, B. N., Perlman, L. V., and Epstein, F. H. (1969). Overweight and hypertension. A review. Circulation, 39, 403-421.

Du Bois, D., and Du Bois, E. F. (1916). Clinical calorimetry. $\mathrm{X}$. A formula to estimate the approximate surface area if height and weight be known. Archives of Internal Medicine, 17, 863-871.

Eich, R. H., Peters, R. J., Cuddy, R. P., Smulyan, H., and Lyons, R. H. (1972). The hemodynamics in labile hypertension. American Heart fournal, 63, 188-195.

Folkow, B., Hallbäck, M., and Weiss, L. (1972). Cardiovascular responses to acute mental 'stress' in spontaneously hypertensive rats (SHR). Acta Physiologica Scandinavica, 84, 7A-8A.

Frohlich, E. D., Kozul, V. J., Tarazi, R. C., and Dustan, H. P. (1970). Physiological comparison of labile and essential hypertension. Circulation Research, 27, Suppl. 1, 55-69.

Harburg, E., Julius, S., McGinn, N. F., McLeod, J., and Hoobler, S. W. (1964). Personality traits and behavioural patterns associated with systolic blood pressure levels in college males. Fournal of Chronic Diseases, 17, 405-414.

Harlan, W. R., Osborne, R. K., and Graybiel. A (1962). A longitudinal study of blood pressure. Circulation, 26, 530543.

Harris, R. E., Sokolow, M., Carpenter, L. G., Jr., Freedman, M., and Hunt, S. P. (1953). Response to psychologic stress in persons who are potentially hypertensive. Circulation, $\mathbf{7}$, 874-879.

Hedstrand, H., and Åberg, H. (1975). A 3-year follow-up of middle-aged men with borderline blood pressure. Acta Medica Scandinavica, 198, 389-395.

Julius, S. (1976). Abnormalities of autonomic nervous control in borderline hypertension. Schweizerische medizinische Wochenschrift, 106, 1698-1705.

Julius, S., EJlis, C. N., Pascual, A. V., Matice, M., Hansson, L., Hunyor, S. N., and Sandler, L. N. (1974). Home blood pressure determination. Value in borderline ('labile') hypertension. Fournal of the American Medical Association, 229, 663-666.

Julius, S., Pascual, A. V., and London, R. (1971). Role of parasympathetic inhibition in the hyperkinetic type of borderline hypertension. Circulation, 44, 413-418.
Julius, S., and Schork, M. A. (1971). Borderline hypertension a critical review. Fournal of Chronic Diseases, 23, 723-754.

Kannel, W. B., Brand, N., Skinner, J. J., Jr., Dawber, T. R., and McNamara, P. M. (1966). The relation of adiposity to blood pressure and development of hypertension. The Framingham study. Annals of Internal Medicine, 67, 48-59.

Kannel, W. B., Schwartz, M. J., and McNamara, P. M. (1969). Blood pressure and risk of coronary heart aisease. The Framingham study. Diseases of the Chest, 56, 43-52.

Karlefors, T. (1966). Exercise tests in male diabetics. II. Heart rate and systolic blood pressure. Acta Medica Scandinavica, 180, Suppl. 449, 19-43.

Karlefors, T., Nilsén, R., and Westling, H. (1966). On the accuracy of indirect auscultatory blood pressure measurements during exercise. Acta Medica Scandinavica, Suppl. $449,81-87$

Larsen, O. A., Lassen, N. A., and Quaade, F. (1966). Blood flow through human adipose tissue determined with radioactive xenon. Acta Physiologica Scandinavica, 66, 337-345.

Lund-Johansen, P. (1967). Hemodynamics in early essential hypertension. Acta Medica Scandinavica, 183, Suppl. 482.

Paffenbarger, R. S., Thorne, M. C., and Wing, A. L. (1968), Chronic disease in former college students. VIII. Characteristics in youth predisposing to hypertension in later years. American fournal of Epidemiology, 88, 25-32.

Pollack, A. A., and Gudger, J. R. (1959). Benign hypertension. Archives of Internal Medicine, 103, 758-761.

Punsar, S., Pyörälä, K., and Siltanen, P. (1968). Classification of electrocardiographic S-T segment changes in epidemiological studies of coronary heart disease. Annales Medicinae Internal Fenniae, 57, 53-63.

Rose, G. A., and Blackburn, H. W. (1968). Cardiovascular survey methods. World Health Organization. Monograph Series, No. 56.

Rushmer, R. F. (1961). Cardiovascular Dynamics, 2nd ed. W. B. Saunders, Philadelphia and London.

Sannerstedt, R. (1966). Hemodynamic response to exercise in patients with arterial hypertension. Acta Medica Scandinavica, 180, Suppl. 458.

Sannerstedt, R. (1969). Hemodynamic findings at rest and during exercise in mild arterial hypertension. American Fournal of the Medical Sciences, 258, 70-79.

Sannerstedt, R., Sivertsson, R., and Lundgren, Y. (1976). Haemodynamic studies in ycung men with mild blood pressure elevation. Acta Medica Scandinavica, Suppl. 602, 61-67.

Simpson, J. A., Jamieson, G., Dickhaus, D. W., and Grover, R. F. (1965). Effect of size of cuff bladder on accuracy of measurement of indirect blood pressure. American Heart Fournal, 70, 208-215.

Sokolow, M., Werdegar, D., Kain, H. K., and Hinman, A. T. (1966). Relationship between level of blood pressure measured casually and by portable recorders and severity of complications in essential hypertension. Circulation, 34, 279298.

Thulin, T., Andersson, G., and Scherstén, B. (1975). Measurement of blood pressure-a routine test in need of standardization. Postgraduate Medical fournal, 51, 390-395.

Thulin, T., Bengtsson, B., and Scherstén, B. (1978). Assessment of blood pressure variations. Postgraduate Medical fournal. In the press.

Wikstrand, J. (1976). Non-invasive assessment of cardiac function. Thesis, Gotab, Kungälv, Sweden, pp. 77-99.

Zilva, J. F., and Nicholson, J. P. (1960). An obesity index and the significance of bromide space measurements. Clinical Science, 19, 449-456.

Requests for reprints to $\mathrm{Dr}$ Thomas Thulin, The Unit for Community Care Sciences, S-240 10 Dalby, Sweden. 